\title{
EFFECT OF EXERCISE WITH CONTINUOUS AND INTERMITTENT BLOOD FLOW RESTRICTION ON HEMODYNAMICS
}

EFEITO DO EXERCÍCIO COM RESTRIÇÃO DE FLUXO SANGUÍNEO CONTÍNUA E INTERMITENTE

NA HEMODINÂMICA

Artículo Original

\section{EFECTO DEL EJERCICIO CON RESTRICCIÓN DE FLUJO SANGUÍNEO CONTINUO E INTERMITENTE}

\section{EN LA HEMODINÁMICA}

Hidayane Gonçalves da Silva', (1D (Physical Education Professional) Gabriel Rodrigues Neto 2,3 (D) (Physical Education Professional) Wanessa Kelly Vieira Vasconcelos ${ }^{1,2}$ (iD) (Physical Education Professional)

Elísio Alves Pereira-Neto 2,4 (D) (Physiotherapist)

Julio Cesar Gomes da Silva 1,2,3 (ID (Physical Education Professional)

Simoni Teixeira Bittar ${ }^{2,3}$ (DD) (Physiotherapist)

Maria Socorro Cirilo-Sousa ${ }^{1,2}$ (D) (Physical Education Professional)

1. Universidade de Pernambuco/ Universidade Federal da Paraíba (UPE/UFPB), Department of Physical Education, Associate Graduate Program in Physical Education, João Pessoa, Paraíba, Brazil. 2. Universidade Federal da Paraíba (UFPB), Department of Physical Education, Kinanthropometry and Human Development Laboratory, João Pessoa, Paraíba, Brazil. 3. Faculdades Nova Esperança, Nursing and Medical Schools, João Pessoa, Paraíba, Brazil.

4. Innovation, Implementation and Clinical Translation in Health (IIMPACT), Allied Health and Human Performance, University of South Australia, Adelaide, Australia.

\section{Correspondence:}

Hidayane Gonçalves da Silva. Departamento de Educação Física, Programa Associado de Pós-graduação em Educação Física UPE/UFPB, Universidade Federal da Paraíba, Centro de Pesquisa em Ciências do Movimento Humano, Laboratório de Cineantropometria, Cidade Universitária, Sala 06 and 08, Castelo Branco, João Pessoa, Paraíba, Brazil. 58051-900 hiday_50@hotmal.com

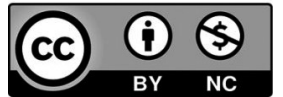

\begin{abstract}
Introduction: Strength training with blood flow restriction (BFR) involves the use of low loads (20-30\% of 1RM) with restriction of blood flow to promote gains in physical fitness. The restriction can be applied continuously or intermittently; however, it is unclear how it affects the hemodynamics of hypertensive women. Objective: To analyze the acute effect of resistance exercise (RE) on the upper and lower limbs with continuous and intermittent blood flow restriction (BFR) on the hemodynamic variables of women with hypertension. Methods: Thirteen women with controlled hypertension (40 to 65 years) underwent eight experimental protocols, with a randomized, counter balanced, crossover design; four exercise sessions for the right upper limb (elbow flexion) and four for the right lower limb (knee extension). The systolic arterial pressure (SAP), diastolic arterial pressure (DAP), and heart rate (HR) were measured before, during, immediately after and 15, 30, 45 and 60 minutes after the exercises. Results: There were no significant interactions between the protocols vs. segments vs. time, protocols vs. segments, protocols vs. time, segments vs. time, protocol, segment and time, on the variables SAP, DAP, and HR during and after the RE ( $p>0.05)$. Although all these protocols had significantly elevated SAP, DAP and $H R$, the values remained within the normal range. The protocols of this study did not cause hypotensive effect. Conclusion: Low-load RE combined with continuous and intermittent BFR, on the upper and lower limbs, appears to promote similar variations in the hemodynamic variables of women with hypertension. Level of evidence ll; Randomized clinical trial.
\end{abstract}

Keywords: Resistance exercise; Vascular occlusion; Hypertension; Post-exercise hypotension.

\section{RESUMO}

Introdução: O exercício de força com restrição de fluxo sanguíneo (RFS) consiste no uso de cargas baixas (20-30\% de 1RM) associado à restrição de fluxo sanguíneo para melhorar o desempenho físico. A restrição pode ser realizada de forma contínua ou intermitente; contudo, não está claro como isso afeta a hemodinâmica de mulheres com hipertensão. Objetivo: Analisar o efeito agudo do exercício de força (EF) no membro superior e inferior com restrição de fluxo sanguíneo (RFS) contínua e intermitente sobre as variáveis hemodinâmicas em mulheres hipertensas. Métodos: Treze mulheres com hipertensão controlada (entre 40 e 65 anos de idade) foram submetidas a oito protocolos experimentais em um estudo randomizado, cruzado e contrabalançado, sendo quatro sessões de exercícios para o membro superior direito (flexão de cotovelo) e quatro sessões de exercícios para o membro inferior direito (extensão de joelho). As medidas das variáveis pressão arterial sistólica (PAS), pressão arterial diastólica (PAD) e frequência cardíaca (FC) foram realizadas antes, durante, imediatamente depois e nos minutos 15, 30, 45 e 60 no período pós-exercício. Resultados: Observou-se que não houve interações significativas entre protocolos $\times$ segmentos $\times$ tempo, protocolos $\times$ segmentos, protocolos $\times$ tempo, segmentos $\times$ tempo, protocolo, segmento e tempo nas variáveis PAS, PAD e FC $e$ durante e depois do EF $(p>0,05)$. Embora todos esses protocolos tenham elevado significativamente a PAS, PAD $e$ $F C$, os valores permaneceram dentro da normalidade. Os protocolos do estudo não promoveram efeito hipotensor. Conclusão: O EF de baixa carga combinado com RFS contínua e intermitente, no membro superior e inferior, parece promover alterações similares nas variáveis hemodinâmicas em mulheres hipertensas. Nível de evidência ll; Estudo clínico randomizado.

Descritores: Exercício de força; Oclusão vascular; Hipertensão; Hipotensão pós-exercício.

\section{RESUMEN}

Introducción: El ejercicio de fuerza con restricción de flujo sanguíneo (RFS) consiste en el uso de cargas bajas (20 a 30\% de 1RM) asociado a la restricción de flujo sanguíneo para mejorar el desempeño físico. La restricción puede ser realizada de forma continua o intermitente; sin embargo, no está claro cómo esto afecta a la hemodinámica de mujeres con hipertensión. Objetivo: Analizar el efecto agudo del ejercicio de fuerza (EF) en el miembro superior e inferior con restricción de flujo sanguíneo (RFS) continua e intermitente sobre las variables 
hemodinámicas en mujeres hipertensas. Métodos: Trece mujeres con hipertensión controlada (entre 40 y 65 años de edad), fueron sometidas a ocho protocolos experimentales en un estudio aleatorizado, cruzado y contrabalanceado, siendo cuatro sesiones de ejercicios para el miembro superior derecho (flexión de codo) y cuatro sesiones de ejercicios para el miembro inferior derecho (extensión de rodilla). Las medidas de las variables presión arterial sistólica (PAS), presión arterial diastólica (PAD) y frecuencia cardíaca (FC) se realizaron antes, durante, inmediatamente después y en los minutos 15, 30, 45 y 60 en el período post-ejercicio. Resultados: Se observó que no hubo interacciones significativas entre protocolos $\times$ segmentos $\times$ tiempo, protocolos $\times$ segmentos, protocolos $\times$ tiempo, segmentos $\times$ tiempo, protocolo, segmento y tiempo en las variables PAS, PAD y FC y durante y después del EF ( $p>0,05)$. Aunque todos estos protocolos hayan elevado significativamente la PAS, PAD, y FC, los valores permanecieron dentro de la normalidad. Los protocolos del estudio no promovieron un efecto hipotensor. Conclusión: El EF de baja carga combinado con RFS continua e intermitente, en el miembro superior e inferior, parece promover alteraciones similares en las variables hemodinámicas en mujeres hipertensas. Nivel de evidencia Il;. Ensayo clínico aleatorizado.

Descriptores: Ejercicio de fuerza; Oclusión vascular; Hipertensión; Hipotensión posejercicio.

\section{INTRODUCTION}

Resistance exercise (RE) has been recommended to people with hypertension two to three times per week with 8 to 10 exercises for the main muscle groups, prioritizing the unilateral execution with one to three series of 10 to 15 repetitions until moderate fatigue and intervals from 90 to 120 seconds. 'However, people with hypertension often do not perform RE due to a fear it may lead to an unsafe cardiovascular event and, consequently, increasing the risk of mortality.

A possible alternative to high load (HL) RE for this population, is the method called RE combined with blood flow restriction (BFR), which is performed with low loads (20-30\% of 1-RM) and consists on the using of inflatable cuffs or elastic bands placed on the proximal portion of the exercising muscles, which has been shown to promote significant changes aerobic capacity, muscle strength and hypertrophy. ${ }^{2}$

Investigations on the BFR effects in hemodynamics usually use continuous ${ }^{3-8}$ (cuff remains inflated between sets) or intermittent $t^{4-6,9-11}$ (pressure released between sets) BFR and usually exercise only the upper or lower limbs. As mode of BFR application and limbs exercised may influence in the effects of exercise on hemodynamic variables, this can implicate a safety issue for the application of BFR specially in clinical populations such as people with hypertension. ${ }^{12}$

This study aimed to compare the changes promoted during RE sessions with continuous and intermittent BFR on the upper and lower limbs on hemodynamic variables in hypertensive women.

\section{MATERIALS AND METHODS}

\section{Subjects}

Thirteen physically active women (performed physical activity with moderate intensity, three times a week, for 60 minutes) ${ }^{13}$ with hypertension aging between 40 and 65 years participated in the study. (Table 1) Sampling was performed on the software G*Power 3.1, according to the procedures proposed by Beck. ${ }^{14}$ Using a priori analysis, with power of $0.80, a=0,05$, correlation coefficient of 0.5 , non-sphericity correction of 1 and an effect size of 0.30 , the sample size was sufficient to provide $80.0 \%$ of the statistic power.

Inclusion criteria were: have stage 1 controlled hypertension (SBP 140-159 mmHg and DBP 90-99 mmHg), ${ }^{1}$ body mass index between 18.3 and $35.0 \mathrm{Kg} / \mathrm{m}^{2}$, ankle-brachial index (ABI) between 0.90 and $1.4,{ }^{15}$ free of target organ damage and/or musculoskeletal and other cardiometabolic diseases that could interfere in the execution of RE protocols, non-smokers.

All subjects were taking the following anti-hypertensive drugs once a day, in the morning: angiotensin receptor antagonist (or ACE inhibitor)
Table 1. Subjects caracteristics $(n=13)$.

\begin{tabular}{c|c}
\hline Variable & Subjects $(\mathbf{n}=13)$ \\
\hline Age (Years) & $55 \pm 6.5$ \\
\hline Body mass $(\mathrm{kg})$ & $73.2 \pm 14.1$ \\
\hline Height $(\mathrm{cm})$ & $1.54 \pm 0.07$ \\
\hline BMI $\left(\mathrm{kg} / \mathrm{m}^{2}\right)$ & $30.4 \pm 4.5$ \\
\hline SAP & $126.5 \pm 17.5$ \\
\hline DAP & $76.6 \pm 13.9$ \\
\hline MAP & $93.2 \pm 14.1$ \\
\hline HR & $76.7 \pm 13.2$ \\
\hline DP & $9821.6 \pm 2666.8$ \\
\hline RBAl (mmHg) & $0.93 \pm 0.08$ \\
\hline LBAl (mmHg) & $0.91 \pm 0.06$ \\
\hline Drugs & $10^{*}$ \\
\hline Angiotensin receptor antagonist (or ACE inhibitor) & $4^{*}$ \\
\hline Diuretic &
\end{tabular}

BMI: Body mass index; SAP: Systolic arterial pressure; DAP: Diastolic arterial pressure; MAP: Mean arterial pressure FC: Heart rate; DP: Double product; RBAl: Right brachial-ankle index; LBAl: Left brachial-ankle index.

(50 $\mathrm{mg}$ ) and diuretic $(25 \mathrm{mg})$. After being explained about the risk and benefits of the research, informed consent was sought according to the Helsinki Declaration. The study was approved by the local Ethics Committee (protocol no 0476/13).

\section{Study design}

Brachial-ankle index (BAI), blood pressure (BP), determination of the blood flow restriction point, anthropometric measures and 1-RM test were assessed on the first visit to the laboratory. Subjects returned 48 hours later to perform the reproducibility of the 1-RM test and the familiarization with the exercises with and without BFR. After familiarization, participants went to the laboratory in eight different days, separated by 48 hours, to execute eight different exercise protocols (P).

All the exercise protocols were performed on the same time of the day, during the afternoon, to control the daily variation of blood pressure and heart rate. The participants were instructed to not eat two hours before the experimental sessions, avoid ingestion of caffeine, chocolate, to not perform exercises 24 hours before the training sessions and to not use the Valsalva maneuver during exercises.

\section{Procedures}

\section{Determination of blood flow restriction (BFR)}

Determination of restriction pressure was performed according to the protocol by Laurentino et al. ${ }^{16}$ Subjects rested in the supine position for 10 minutes while a cuff (Riester', Jungingen, Alemanha) was placed on the proximal portion of the arm $(6 \times 47 \mathrm{~cm})$ and leg $(10 \times 54 \mathrm{~cm})$. The cuff was 
inflated until the moment when the auscultatory pulse of the brachial artery (right upper limb) or posterior tibial artery (right lower limb) ceased, with the value in $\mathrm{mmHg}$ being considered as 100\% of BFR. The auscultatory pulse was verified using a portable doppler (DV2001, Medpej, Ribeirão Preto, São Paulo) in which the probe was placed on the skin on the path of the artery with a $60^{\circ}$ inclination from the longitudinal axis of the vessel. The pressure used on the experimental sessions was $50 \%$ of the blood flow restriction pressure in $\mathrm{mmHg}$. Average pressure for BFR protocols were $89,23 \pm 10,37$

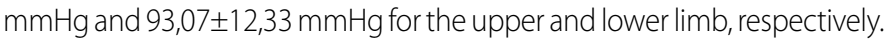

\section{One repetition maximum (1-RM)}

For the warm-up, each subject performed a series of five to ten repetitions at 40 to $60 \%$ of the maximum strength perceived with a one-minute interval between series. After the one-minute interval, the strength assessment began and the subjects should reach their maximum strength in no more than five attempts, the load was adjusted at each new attempt. The recovery time between each attempt was from 3 to 5 minutes and a 15 minutes interval was stablished between exercises. The test was interrupted when the individual could not execute correctly the movement, being considered as the 1-RM, the load lifted on the last well-succeed attempt.

\section{Systolic and diastolic arterial pressure, and heart rate}

The hemodynamic variables were measured with the subject on rest, during and after the exercise, by the oscillometric method using the Blood Pressure Monitoring Device (BPMD) G-Tech model BP3MZ1 and all the measures were performed as it follows, according to the recommendations of the Brazilian Cardiology Society: ${ }^{17}$ a) Rest: firstly, the subjects remained in sitting position for ten minutes in a calm environment with no noises and little light, for the accomplishment of the measures of SAP, DAP and HR, being obtained the mean of three measures with a five minute interval; b) During: the measures of SAP, DAP and HR were performed at the end of each series; c) After the exercise: the subjects remained in the room, sitting for 1 hour, to perform the SAP, DAP and HR measurements at 15, 30, 45 and 60 minutes, totaling 13 measurements.

\section{Experimental sessions}

The following protocols were performed: (P1/P5) high load RE with $65 \%$ of 1-RM (HLRE); (P2/P6) low load RE with 20\% of 1-RM (LLRE); (P3/ P7) low load resistance exercise with continuous blood flow restriction with $20 \%$ of 1 -RM and addition of $50 \%$ of BFR (LL+CBFR); (P4/P8) low load resistance exercise with intermittent blood flow restriction with $20 \%$ of 1-RM and addition of $50 \%$ of BFR ( $L L+\mid B F R$ ); BFR ( $L L+C B F R)$; Being P1-P4 for the upper and P5-P8 for the lower limbs, totaling eight experimental protocols. For all protocols, the sessions consisted of four sets of unilateral right elbow flexion using halters and four sets of unilateral right knee extension on the extensor chair, with speed execution of two seconds for each phase of the movement.

\section{Statistical analysis}

The data was analyzed on the statistical software Statistical Package for the Social Science (SPSS) version 20.0. Analysis to verify normality (Shapiro-Wilk test), homogeneity (Levene test) and sphericity (Mauchly test) of data was performed. To verify possible significant differences on the dependent variables the repeated measures ANOVA between (protocols $\times$ segments $\times$ time), (protocols $\times$ segments), (protocols $\times$ time), (segments $\times$ time), (protocols) and (segment) followed by Bonferroni post-hoc were conducted. Effect size (ES) was used the verify the magnitude [trivial < 0.35 , small $=0.35-0.80$, moderate $=0.80-1.50$ e large $>1.5]$ of the changes between the evaluations of the study protocols (RHEA, 2004), and was used the percent variation $(\triangle \%)$, to express the possible differences between significant changes. Significance was stablished as $p<0.05$

\section{RESULTS}

\section{Systolic arterial pressure (SAP)}

No significant interactions were found between protocols $\times$ segments $x$ time, protocols $\times$ segments, protocols $\times$ time, segments $\times$ time, protocol and segment ( $p>0.05)$. However, a significant interaction was found on time $(p<0.001)$. After post-hoc analysis, it was verified that in the $L L+C B F R$ protocol there was a significant increase on the right upper limb when comparing the $1^{\text {st }}$ and $2^{\text {nd }}$ series with rest $(p=0.027, \Delta \%=11.1, E S=0.7$ and $p=0.045, \Delta \%=10.7, E S=0.7$, respectively), and in the lower limb, when compared to $2^{\text {nd }}, 3^{\text {rd }}$ and $4^{\text {th }}$ series with rest $(p=0.016, \Delta \%=11.7, E S=1.0$, $p=0.028, \Delta \%=11.5, E S=1.0$ and $p=0.008, \Delta \%=12.1, E S=1,0$, respectively).

In the $L L+\mid B F R$ protocol, there was a significant increase for the right upper limb when comparing the $2^{\text {nd }}$ series with rest $(p=0.006, \Delta \%=12.9$, $E S=1.0)$ and for the right lower from rest to the $4^{\text {th }}$ series $(p=0.002$, $\Delta \%=13.6, E S=1.1)$. In the $L L$ protocol there was significant increase from the $2^{\text {nd }}$ series vs. rest $(p=0.032, \Delta \%=11.0, E S=0.6)$ on the right lower limb. However, there was no significant increase throughout the session nor significant reductions after exercise on the right upper limb ( $p>0.05)$ nor for the HL protocol, on both upper and lower right limb, throughout the session when comparing series vs. rest ( $p>0.05$ ), as shown in Table 2 .

\section{Diastolic arterial pressure (DAP)}

No significant interactions were found between protocols $\times$ segments $\times$ time, protocols $\times$ segments, protocols $\times$ time, segments $\times$ time, protocol and segment ( $p>0.05)$. However, significant interactions were found on time $(p<0.001)$. After the post-hoc analysis, it was verified that in the $L L+C B F R$ on the right upper limb there was a significant increase when comparing the $1^{\text {st }}, 2^{\text {nd }}, 3^{\text {rd }}$ and $4^{\text {th }}$ series with rest $(p=0.000, \Delta \%=$ $21.8, E S=0.9 ; p=0.000, \Delta \%=24.8, E S=1.0 ; p=0.000, \Delta \%=20.2, E S=$ $0.8 ;$ and $\mathrm{p}=0.001, \Delta \%=16.8, \mathrm{ES}=0.7$, respectively). Regarding the right lower limb, there were no significant increase during exercise ( $p>0.05)$.

Table 2. Comparative analysis of systolic arterial pressure between the protocols of the study during and after exercise.

\begin{tabular}{|c|c|c|c|c|c|c|c|c|}
\hline \multirow{2}{*}{$\frac{\text { SAP }(\mathrm{mmHg})}{\text { Rigth side }}$} & \multicolumn{2}{|c|}{$\mathrm{LL}+\mathrm{CBFR}$} & \multicolumn{2}{|c|}{ LL+IBFR } & \multicolumn{2}{|c|}{ LL } & \multicolumn{2}{|c|}{$\mathrm{HL}$} \\
\hline & Upper limb & Lower limb & Upper limb & Lower limb & Upper limb & Lower limb & Upper limb & Lower limb \\
\hline Rest & $127.8 \pm 19.4$ & $126.5 \pm 14.6$ & $123.6 \pm 15.4$ & $123.3 \pm 14.7$ & $129.6 \pm 22.5$ & $127.5 \pm 20.3$ & $123.0 \pm 17.6$ & $130.9 \pm 17.4$ \\
\hline $1^{\text {st }}$ series & $142.0 \pm 24.7$ & $138.6 \pm 20.7$ & $131.6 \pm 15.1$ & $134.1 \pm 18.8$ & $138.2 \pm 18.0$ & $137.3 \pm 16.0$ & $129.6 \pm 14.8$ & $136.8 \pm 16.7$ \\
\hline $2^{\text {nd }}$ series & $141.6 \pm 15.1^{*}$ & $141.4 \pm 13.9^{*}$ & $139.6 \pm 18.1^{*}$ & $132.0 \pm 11.5$ & $135.7 \pm 18.5$ & $141.6 \pm 13.5^{*}$ & $130.3 \pm 15.3$ & $140.9 \pm 21.1$ \\
\hline $3^{\text {rd }}$ series & $139.6 \pm 22.3$ & $141.1 \pm 18.8$ & $136.9 \pm 16.3$ & $136.1 \pm 21.2$ & $132.5 \pm 15.7$ & $138.8 \pm 16.1$ & $128.9 \pm 19.8$ & $141.1 \pm 18.3$ \\
\hline \multirow[t]{2}{*}{$4^{\text {th }}$ series } & $135.8 \pm 20.5$ & $141.9 \pm 21.5$ & $134.9 \pm 15.6$ & $140.1 \pm 19.6^{*}$ & $134.2 \pm 18.9$ & $140.3 \pm 18.3$ & - & - \\
\hline & Upper limb & Lower limb & Upper limb & Lower limb & Upper limb & Lower limb & Upper limb & Lower limb \\
\hline 15 min after & $126.0 \pm 22.1$ & $122.1 \pm 21.7$ & $125.0 \pm 17.8$ & $124.0 \pm 16.2$ & $126.0 \pm 20.3$ & $130.4 \pm 20.2$ & $123.0 \pm 20.6$ & $128.5 \pm 16.4$ \\
\hline 30 min after & $119.8 \pm 23.9$ & $126.3 \pm 18.8$ & $124.6 \pm 19.6$ & $127.0 \pm 14.7$ & $122.6 \pm 19.0$ & $126.7 \pm 19.1$ & $123.0 \pm 20.4$ & $127.0 \pm 16.8$ \\
\hline 45 min after & $128.2 \pm 20.7$ & $128.4 \pm 19.0$ & $127.1 \pm 18.1$ & $123.3 \pm 15.2$ & $126.4 \pm 18.5$ & $128.7 \pm 17.4$ & $125.9 \pm 19.2$ & $125.4 \pm 17.8$ \\
\hline 60 min after & $133.5 \pm 19.7$ & $130.0 \pm 23.8$ & $128.5 \pm 18.2$ & $125.0 \pm 17.3$ & $134.0 \pm 17.4$ & $130.3 \pm 18.5$ & $128.7 \pm 17.4$ & $131.3 \pm 21.1$ \\
\hline
\end{tabular}

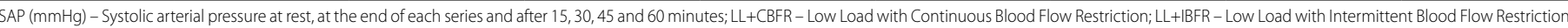
LL - Low Load; HL - High Load; * Significant difference when comparing with rest $(\mathrm{p}<0,05)$. 
In the LL+IBFR protocol, on the right upper limb there was a significant increase when comparing the $1^{\text {st }}, 2^{\text {nd }}, 3^{\text {rd }}$ and $4^{\text {th }}$ series with rest ( $p$ $=0.016, \Delta \%=15.8, E S=1.0 ; p=0.001, \Delta \%=19.3, E S=1.2 ; p=0.000$, $\Delta \%=20.5, E S=1.3 ;$ and $p=0.001, \Delta \%=16.4, E S=1.0$, respectively), and for the right lower limb, comparing the 3rd and 4th series with rest ( $p=$ $0.004, \Delta \%=14.5, E S=0.6$; and $p=0.036, \Delta \%=13.3, E S=0.5$, respectively).

Regarding the $\mathrm{LL}$ protocol, on the right upper limb there was a significant increase on the $3^{\text {rd }}$ series vs. rest $(p=0.005, \Delta \%=8.5, E S=0.6)$. As for the right lower limb, only after the $3^{\text {rd }}$ series a significant increase was observed ( $p=0.010, \Delta \%=12.9$, ES $=0.7$ ). For the $\mathrm{HL}$ protocol, on both right upper and lower limb there was no significant increase throughout the session when comparing series vs. rest ( $p>0.05)$, as shown in Table 3.

\section{Heart rate (HR)}

There were no significant interactions between protocols $\times$ segments $\times$ time, protocols $\times$ segments, protocols $\times$ time, segments $\times$ time, protocol and segment ( $p>0.05)$, however, there were significant interactions in time $(p<0.001)$. After post hoc $H R$ analysis it was found that in the $L L+C B F R$ protocol in both the right upper and lower limbs there was no significant increase throughout the session of the series vs. ( $p>0.05)$. In the LL+|BFR protocol, in the right upper limb there was a significant increase comparing the $2^{\text {nd }}$ and $4^{\text {th }}$ series with rest $(p=0.001$, $\Delta \%=12.3, E S=0.6$; and $p=0.048, \Delta \%=8.7, E S=0.4$ ). On the other hand, in the right lower limb there was no significant increase throughout the session of the series vs. ( $p>0.05$ ), not even in the $\mathrm{LL}$ and $\mathrm{HL}$ protocols, on both upper and lower right limb, during the session of the series compared to rest ( $p>0.05)$, as shown in Table 4.

\section{DISCUSSION}

The present study analyzed the acute effect of RE performed on the upper or lower right limb, combined with continuous or intermittent BFR on the hemodynamic variables. To our knowledge, this was the first study to analyze those interactions in people with hypertension. The main findings were: a) there were no significant changes on the SAP, DAP, and HR when comparing continuous and intermittent BFR or upper and lower right limb, although all these protocols elevated significantly the SAP, DAP, and HR within the expected; b) the protocols of the study did not promote hypotensive effect.

The results of the present study provide evidenced that there were no significant changes on the hemodynamic variables between the treatment protocols during and after the sessions. However, it is possible to verify that a greater increase happened during the session of the protocols with both intermittent and continuous BFR on the upper and lower limb than in the $\mathrm{LL}$ and $\mathrm{HL}$ protocols without BFR. This phenomenon may have occurred due to an increased metabolic stress caused by hypoxia on the BFR protocols, as observed in the study by Pinto et al. ${ }^{8}$ where one session of BFR without exercise elevated the hemodynamic variables compared to rest.

Higher percentages of BFR apparently result in greater elevations of the hemodynamic variables. ${ }^{4}$ In the study by Brandner et al. ${ }^{4}$ it was observed that during exercise the SAP and DAP between the IBFR and $\mathrm{HL}$ protocols were similar, however the changes on the BP during the IBFR protocol were greater than the CBFR and LL protocols. The possible explanation is that for the IBFR protocol $130 \%$ of the rest pressure was used to promote restriction and only $80 \%$ for the CBFR, becoming evident that the percentage of pressure used is a regulator factor for the magnitude of the hemodynamic responses.

The training protocols did not promote the post-exercise hypotensive effect, with a similar response reported by Brandner et al. ${ }^{4}$ that investigated the impact of intermittent and continuous BFR in normotensive individuals. Contrariwise, other studies that investigated the impact of continuous and intermittent BFR in normotensive male ${ }^{5,6}$ and continuous BFR in women with hypertension ${ }^{7}$ showed different results. The reason for these distinct outcomes may be related to the difference on the methods used on the studies.

The studies by Araújo et al., ${ }^{7}$ performed with hypertensive women, Rodrigues Neto et al. ${ }^{5}$ and Rodrigues Neto et al., ${ }^{6}$ which investigated normotensive men, observed a hypotensive effect after BFR, however used protocols with higher volumes and multi-joint exercises. Higher training volumes and more complex exercises seem to be capable of increasing sympathetic and reducing parasympathetic activity changing the behavior of the hemodynamic variables during exercise and, consequently, provoking more significant decreases of blood pressure after exercise. ${ }^{18}$

Table 3. Comparative analysis of diastolic arterial pressure between the protocols of the study during and after exercise.

\begin{tabular}{c|c|c|c|c|c|c|c|c}
\hline DAP $(\mathbf{m m H g})$ & \multicolumn{2}{|c|}{ LL+CBFR } & \multicolumn{2}{c|}{ LL+IBFR } & \multicolumn{2}{c|}{ LL } & \multicolumn{2}{c}{ HL } \\
\hline Right side & Upper limb & Lower limb & Upper limb & Lower limb & Upper limb & Lower limb & Upper limb & Lower limb \\
\hline Rest & $74.9 \pm 17.2$ & $80.5 \pm 13.3$ & $75.5 \pm 11.9$ & $72.7 \pm 16.3$ & $77.3 \pm 10.8$ & $76.6 \pm 13.1$ & $76.4 \pm 16.0$ & $78.7 \pm 14.0$ \\
\hline $1^{\text {st }}$ series & $91.3 \pm 26.6^{*}$ & $85.5 \pm 13.5$ & $87.5 \pm 14.1^{*}$ & $82.6 \pm 13.1$ & $87.2 \pm 12.9$ & $81.9 \pm 13.1$ & $83.1 \pm 12.1$ & $84.0 \pm 9.6$ \\
\hline $2^{\text {nd }}$ series & $93.5 \pm 16.7^{*}$ & $87.3 \pm 13.4$ & $90.1 \pm 21.6^{*}$ & $81.3 \pm 14.9$ & $88.1 \pm 13.5$ & $85.3 \pm 11.6$ & $80.9 \pm 16.3$ & $84.0 \pm 10.3$ \\
\hline $3^{\text {rd }}$ series & $90.1 \pm 17.9^{*}$ & $85.6 \pm 12.9$ & $91.0 \pm 13.3^{*}$ & $83.3 \pm 17.0^{*}$ & $87.6 \pm 14.3^{*}$ & $86.5 \pm 13.3^{*}$ & $82.4 \pm 10.9$ & $81.5 \pm 12.5$ \\
\hline $4^{\text {th }}$ series & $87.5 \pm 13.9^{*}$ & $83.0 \pm 13.0$ & $87.9 \pm 16.6^{*}$ & $82.4 \pm 16.6^{*}$ & $85.1 \pm 15.6$ & $85.3 \pm 13.4$ & - & - \\
\hline & Upper limb & Lower limb & Upper limb & Lower limb & Upper limb & Lower limb & Upper limb & Lower limb \\
\hline 15 min after & $76.3 \pm 14.5$ & $78.2 \pm 15.4$ & $76.3 \pm 14.7$ & $77.1 \pm 14.9$ & $77.3 \pm 16.2$ & $79.6 \pm 18.3$ & $74.7 \pm 15.0$ & $76.9 \pm 14.0$ \\
\hline 30 min after & $74.9 \pm 15.5$ & $77.1 \pm 16.0$ & $76.3 \pm 14.2$ & $75.8 \pm 12.6$ & $77.1 \pm 15.2$ & $79.0 \pm 15.3$ & $72.7 \pm 14.8$ & $76.5 \pm 12.7$ \\
\hline 45 min after & $78.0 \pm 13.2$ & $77.6 \pm 12.8$ & $78.6 \pm 13.2$ & $76.6 \pm 13.4$ & $77.4 \pm 15.6$ & $80.3 \pm 15.4$ & $74.9 \pm 15.8$ & $77.6 \pm 15.2$ \\
\hline 60 min after & $80.3 \pm 13.8$ & $80.0 \pm 15.8$ & $80.2 \pm 13.4$ & $77.5 \pm 12.2$ & $81.0 \pm 16.1$ & $82.8 \pm 14.3$ & $79.0 \pm 14.9$ & $79.0 \pm 13.6$ \\
\hline
\end{tabular}

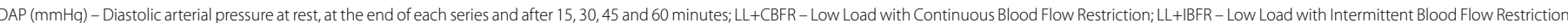
LL - Low Load; HL - High Load; * Significant difference when comparing with rest $(p<0,05)$.

Table 4. Comparative analysis of heart rate between the protocols of the study during exercise.

\begin{tabular}{|c|c|c|c|c|c|c|c|c|}
\hline \multirow{2}{*}{$\begin{array}{l}\text { HR (bpm) } \\
\text { Right side }\end{array}$} & \multicolumn{2}{|c|}{ LL+CBFR } & \multicolumn{2}{|c|}{ LL+IBFR } & \multicolumn{2}{|c|}{ LL } & \multicolumn{2}{|c|}{$\mathrm{HL}$} \\
\hline & Upper limb & Lower limb & Upper limb & Lower $\operatorname{limb}$ & Upper limb & Lower limb & Upper limb & Lower limb \\
\hline Rest & $78.3 \pm 11.6$ & $75.6 \pm 15.1$ & $72.0 \pm 13.9$ & $76.6 \pm 16.0$ & $78.6 \pm 13.5$ & $77.3 \pm 12.5$ & $78.0 \pm 13.5$ & $77.0 \pm 11.0$ \\
\hline $1^{\text {st }}$ series & $81.2 \pm 17.2$ & $76.9 \pm 14.3$ & $77.1 \pm 16.1$ & $76.2 \pm 15.1$ & $82.4 \pm 15.2$ & $82.0 \pm 13.5$ & $80.7 \pm 14.6$ & $78.3 \pm 11.6$ \\
\hline $2^{\text {nd }}$ series & $80.5 \pm 12.9$ & $76.0 \pm 14.4$ & $80.9 \pm 17.4^{*}$ & $76.9 \pm 15.4$ & $83.3 \pm 16.8$ & $79.9 \pm 13.0$ & $80.3 \pm 13.1$ & $78.3 \pm 11.5$ \\
\hline $3^{\text {rd }}$ series & $80.0 \pm 14.0$ & $75.4 \pm 14.3$ & $77.9 \pm 15.5$ & $76.3 \pm 15.6$ & $82.3 \pm 15.0$ & $79.5 \pm 13.0$ & $80.8 \pm 13.9$ & $78.0 \pm 10.9$ \\
\hline $4^{\text {th }}$ series & $80.6 \pm 14.5$ & $74.8 \pm 15.6$ & $78.3 \pm 15.1^{*}$ & $77.5 \pm 15.2$ & $82.4 \pm 15.7$ & $80.1 \pm 12.3$ & - & - \\
\hline
\end{tabular}

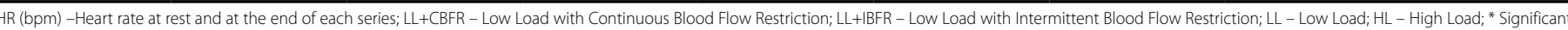
difference when comparing with rest $(p<0,05)$ 
As limitations of this study, we can highlight the quantity of exercise performed that was only one for both the right upper limb (unilateral elbow flexion) and for the right lower limb (unilateral knee extension) and the protocols were equivalent, therefore the findings of this study cannot be extrapolated for other exercises.

\section{CONCLUSION}

Low load RE combined with continuous and intermittent BFR, on the upper and lower limbs, promoted similar changes on the hemodynamic variables. The RE with IBFR seems to be more suitable to be performed by clinical populations (i.e. people with hypertension and elderly) as it promoted lower elevations on hemodynamic variables during exercise. It is suggested that new studies carry out a resistance training program with continuous and intermittent BFR using different exercises (within the session) and with bilateral execution to verify changes in hemodynamics in patients with hypertension.

All authors declare no potential conflict of interest related to this article

AUTHORS' CONTRIBUTIONS: Each author made significant individual contributions to this manuscript: HGS: Elaboration of the research design, data collection, and writing the manuscript; GRN: Statistical analysis and interpretation of the data in the manuscript; WKW: Collection and tabulation of the data in the manuscript; EAPN: Statistical analysis and interpretation of the data in the manuscript; JCGS: Discussion of the results in the manuscript; STB: Critical review of the intellectual content of the manuscript; MSCS: Substantial contribution to the conception and final approval of the version of the manuscript to be published.

\section{REFERENCES}

1. Malachias MVB, Gomes MAM, Nobre F, Alessi A, Feitosa AD, Coelho EB. 7a Diretriz Brasileira De Hipertensão Arterial. Arq Bras Cardiol. 2017;107(3):1-83.

2. Pope ZK, Willardson JM, Schoenfeld BJ. Exercise and blood flow restriction. J Strength Cond Res. 2013;27(10):2914-26.

3. Rossow LM, Fahs CA, Loenneke JP, Thiebaud RS, Sherk VD, Abe T. Cardiovascular and perceptual responses to blood-flow-restricted resistance exercise with differing restrictive cuffs. Clin Physiol Funct Imaging. 2012;32(5):331-7.

4. Brandner CR, Kidgell DJ, Warmington SA. Unilateral bicep curl hemodynamics: Low-pressure continuous vs high-pressure intermittent blood flow restriction. Scand J Med Sci Sport. 2015;25(6):770-7.

5. Rodrigues Neto G, Novaes JS, Salerno VP, Gonçalves MM, Piazera BKL, Rodrigues-Rodrigues T. Acute effects of resistance exercise with continuous and intermittent blood flow restriction on hemodynamic measurements and perceived exertion. Percept Mot Skills. 2017;124(1):227-92.

6. Rodrigues Neto G, Novaes JS, Gonçalves M, Batista GR, Mendonça RMSC, Miranda H. Hypotensive effects of resistance exercise with continuous and intermittent blood flow restriction. Motriz: rev educ fis. 2016;22(3):198-204.

7. Araújo JP, Silva ED, Silva JCG, Souza TSP, Lima EO, Guerra I. The Acute Effect of Resistance Exercise with Blood Flow Restriction with Hemodynamic Variables on Hypertensive Subjects. J Hum Kinet. 2014;43(1):79-85.

8. Pinto RR, Karabulut M, Poton R, Polito MD. Acute resistance exercise with blood flow restriction in elderly hypertensive women: Haemodynamic, rating of perceived exertion and blood lactate. Clin Physiol Funct Imaging. 2016;38(1):1-8.
9. Kacin A, Strazar K. Frequent low-load ischemic resistance exercise to failure enhances muscle oxygen delivery and endurance capacity. Scand J Med Sci Sports. 2011;21(6):231-41.

10. Rodrigues Neto G, Cirilo-Sousa MS, Costa PB, Salles BF, Novaes GS, Novaes JS. Hypotensive effects of resistance exercises with blood flow restriction. J strength Cond Res. 2015;29(4):1064-70.

11. Figueroa A, Vicil F. Post-exercise aortic hemodynamic responses to low-intensity resistance exercise with and without vascular occlusion. Scand J Med Sci Sports. 2011;21(3):431-6.

12. Spranger MD, Krishnan AC, Levy PD, Leary DSO, Smith SA. Blood flow restriction training and the exercise pressor reflex : a call for concern. Am J Physiol Circ Physiol. 2015;309(9):1440-52.

13. Nelson ME, Rejeski WJ, Blair SN, Duncan PW, Judge JO, King AC. Physical Activity and Public Health in Older Adults Recommendation From the American College of Sports Medicine and the American Heart Association. Circulation. 2007;116(9):1094-105.

14. Beck TW. The importance of a priori sample size estimation in strength and conditioning research. J Strength Cond Res. 2013;27(8):2323-37.

15. Resnick HE, Lindsay RS, McDermott MM, Devereux RB, Jones KL, Fabsitz RR. Relationship of High and Low Ankle Brachial Index to All-Cause and Cardiovascular Disease Mortality: The Strong Heart Study. Circulation. 2004;109(6):733-9.

16. Laurentino GC, Ugrinowitsch C, Aihara AY, Ferandes AR, Parcell AC, Tricoli V. Effects of Strength Training and Vascular Occlusion. J Sport Sci Med. 2008;29(8):664-7.

17. Cardiologia SB. V Diretrizes de Monitorização Ambulatorial da Pressão Arterial (MAPA) e III Diretrizes de Monitorização Residencial da Pressão Arterial (MRPA). Arq Bras Cardiol. 2011;97(3):1-24.

18. Polito MD, Farinatti PTV. The effects of muscle mass and number of sets during resistance exercise on postexercise hypotension. J Strength Cond Res. 2009;23(8):2351-7. 